\title{
Methodological safety management issues of socio-economic entities
}

\author{
Evgeniy Bikmetov ${ }^{1,}{ }^{*}$, Liliya Amirkhanova ${ }^{1}$, Natalya Galimullina ${ }^{2}$, Zarina Sizonenko ${ }^{2}$, and \\ Oksana Ignatyeva ${ }^{2}$
}

${ }^{1}$ Ufa State Aviation Technical University, K. Marx str., 12, 450008 Ufa, Russia

${ }^{2}$ Bashkir State University, Z. Validi str., 32, 450076 Ufa, Russia

\begin{abstract}
The article examines the methodological safety management basics of economic entities on the example of enterprises and organizations exposed to risks in the modern complex operating conditions. Uncertainty, stochasticity of socio-economic relations give rise to challenges that pose a threat to economic entities. Risks are understood as losses from alternative investments and costs of overcoming the consequences of crisis situations. The expediency of using the proposed methodology due to the occurrence of losses from the expectation damages and the unpredictability of the influence of external and internal factors causing economic damage. The authors propose to use a model that characterizes the relationship between the losses of a socio-economic entity and the number of measures that need to be implemented to eliminate the damage. The article describes an algorithm that allows to assess the capabilities of an enterprise and achieve the stated purpose. This problem statement makes it possible to evaluate all the options for overcoming the crisis and choose the optimal one, which will improve the object performance efficiency. According to the authors, minimizing the threats, understanding the best measures to overcome the crisis and the calculation of total costs are the main factors in achieving the economic effect of the proposed model.
\end{abstract}

\section{Introduction}

The relevance of this study is determined by the need to search for methods of managing the economic safety of the socio-economic entity, since the existing methods are diverse in nature, but are represented by a wide range of methods and techniques, from administrative, economic and ending with psychological and social. All this encourages us to offer a more affordable and reasonable management methods.

The economic security of a subject of any system is determined by the possibility of assessing the emergence of threats and their subsequent elimination or smoothing. This is significant for minimizing the negative impact of external and internal factors $[1,2]$, as well as achieving the prosperity of the object under study. Security management of socioeconomic entity (SEE) is based on the system, expert and comprehensive approaches that distinguish the entity and the subject of management, together constitute a comprehensive

\footnotetext{
* Corresponding author: bicprof@mail.ru
} 
system designed to allow a timely influence on the unfavorable situation; the goal and objectives of improving the safety of the entire system, the principles and mechanisms for influencing adverse factors. Attempts to use organizational theory in the analysis of the transformation of global processes also seem promising [3]. In the course of the study, the following are determined: indicators for assessing the SEE security; depending on the situation, SEE threat parameters and threshold values are assessed; feasibilities of development goal are determined; control actions are defined on the state of the control object by expertise; the influence on the control actions implementation of the control object is estimated. At the same time, security management should be process-oriented, which means consistent performance of such functions of management and economic analysis, as the assessment and planning, under construction on strategic management [4]; organization of activities of subsystems and their coordination [3]; monitoring the exit of the parameters of the object beyond certain boundaries, the formation of analytical conclusions and recommendations [5].

The reasons for failures in the SEE activities are the lack of the necessary control over the current and strategic indicators of the functioning of its various subsystems, improper implementation of the rules and instructions (control actions) on which the management of economic security is based, etc. The object can be out of sight of the management entity. Attention should be focused on the lack of evidence-based approaches to prevent anticipated failures and threats, preventing unexpected (unique) failures. It should be noted that for unique failures, there is usually neither a strategy nor a tactic for taking action to prevent the development of an untoward condition. In this case, the role of forecasting increases [6], since in order to secure the working of system, it is necessary to foresee what certain deviations in its state can lead to.

\section{Literature review and methods}

The theoretical basis of the research were the works in the field of economic security and management of authors such as O. A. Hrunyn [4], J. F. Broder [4], T. D. Giles [8], E. V. Olejnykova [9], O. V. Rossoshanskaya [10] and others.

Most authors distinguish financial, informational, technogenic, environmental, technological, social and other security in the security management system $[11,12,13,14$, 15]. According to the approaches presented in the scientific literature, the concept of "security of socio-economic entity" means the efficient resource utilization and capabilities that ensure its functioning in the present and sustainable development in the future, as well as the prevention or mitigation of emerging obstacles and threats to life [9]. When considering this concept, the authors emphasize that the most optimal is the following conceptual construct: hostility, threat, risk, damage, security strategy, negative event, preventive costs, total losses, total costs, profit, efficiency. A number of researchers also discuss the impact of conflict as an internal threat to the economic security of an enterprise [16] and apply various methods of modeling its assessment [17]. It should be noted that in the digital economy, the accents of economic security component and its entities are expanding, the problems of information security at the forefront of information security problems [5.18], new synergetic tools SEE control [19].

However, whatever the type of security, in the end it all comes down to economic security associated with the use of significant financial resources of socio-economic entity to overcome the consequences of failure. These costs are unproductive because they are used to restore the SEE state, but during this time no products and services are created. Therefore, the costs of restoring the state of SEE can be regarded as losses. The increased resources consumption and even unproductive, leads to the fact that SEE becomes 
dependent on other systems (financial, government, legal, consulting). These losses are irreplaceable and require careful study and assessment.

Considering the above, it becomes clear the purpose of this study - to determine the directions for improving the methods of SEE safety management. The authors solve the following tasks:

- criterion selection for the evaluation of the optimal value of SEE damage,

- development of an algorithm for preventing the losses and wastes of SEE,

- search for methods of SEE safety management.

To prevent the occurrence of failure situations, it is necessary to take the preventive measures. SEE is limited in funds and therefore it cannot use all possible measures, but it cannot not be used either. As practice shows, the amount of losses always turns out to be hundreds of times more than the cost of timely implementation of protective measures. In conditions of limited resources, it is necessary to find the optimal number of activities at which the amount of losses will be minimal. It is possible that there will be no failure at all. But at the same time, the financial resources spent on the timely implementation of protective measures will be hundreds of times less than the damage from the failure.

\section{Results and discussion}

The published works substantiate the use of the economic criterion of minimum losses, the terms of which depend on the sphere of SEE functioning [1, 2]. According to the authors, this criterion is very important and support its use in assessing the economic security of SEE. It is proposed to consider as a criterion the total losses from not using the entire set of measures to prevent the failure situations, which is the amount of losses L1 from the alternative use of finance and losses L2 due to the need to spend financial resources to overcome the consequences of an emergency (table 1).

Table 1. Losses from the emergence of threats to economic security of SEE.

\begin{tabular}{|c|l|l|l|l|l|}
\hline No. & Definition & $\begin{array}{l}\text { Evaluation } \\
\text { method }\end{array}$ & $\begin{array}{l}\text { Calculatio } \\
\text { n } \\
\text { methodolo } \\
\text { gys }\end{array}$ & Difficults & Decisions \\
\hline L1 & $\begin{array}{l}\text { amount of } \\
\text { losses from } \\
\text { alternative } \\
\text { use of } \\
\text { finance }\end{array}$ & $\begin{array}{l}\text { expert } \\
\text { method, } \\
\text { discounting }\end{array}$ & $\begin{array}{l}\text { for each } \\
\text { alternative: } \\
\text { 1) the } \\
\text { amount of } \\
\text { investment } \\
\text { costs, lost } \\
\text { benefits } \\
\text { and profits } \\
2) \ldots\end{array}$ & $\begin{array}{l}\text { search for } \\
\text { experts, } \\
\text { limited } \\
\text { information } \\
\text { sources }\end{array}$ & $\begin{array}{l}\text { the creation } \\
\text { of a reserve } \\
\text { base of } \\
\text { experts for } \\
\text { consulting } \\
\text { firms }\end{array}$ \\
\hline L2 & $\begin{array}{l}\text { the amount } \\
\text { of losses to } \\
\text { overcome } \\
\text { the } \\
\text { consequenc } \\
\text { es of a } \\
\text { failure } \\
\text { situation }\end{array}$ & $\begin{array}{l}\text { costing, } \\
\text { budgeting } \\
\text { and } \\
\text { forecasting, } \\
\text { risk } \\
\text { manageme } \\
\text { nt }\end{array}$ & $\begin{array}{l}\text { cost } \\
\text { estimating }\end{array}$ & $\begin{array}{l}\text { determinati } \\
\text { on of the } \\
\text { optimal list } \\
\text { of costs, } \\
\text { lack of } \\
\text { recognition }\end{array}$ & $\begin{array}{l}\text { developme } \\
\text { nt of } \\
\text { guidelines }\end{array}$ \\
\hline $\begin{array}{l}\text { Tot } \\
\text { al }\end{array}$ & & & L1 + L2 & & \\
\hline
\end{tabular}


The loss of L1 can be estimated as a lost profit, which could have been obtained if financial resources had been invested in an innovative project that would expand the market share by quickly bringing a product or service to the market. The loss of L1 from an increase in the number of implemented preventive measures will grow, as the SEE will miss the opportunity to take an additional market share by launching a new product or service.

When displaying the dependence of L2 on the number of preventive events implemented in practice, it is necessary to estimate the amount of losses, as if finances were allocated only for one event. Then, as if two events were implemented, and again assess the damage L2 from the fact that the remaining events were not implemented, etc. In this case, the dependence of the L2 loss on the number of implemented events will decrease, i.e., the more events are taken to prevent failure situations, the less the possible value of L2 will be.

When calculating losses, they must be discounted, since those who suffer losses (material, physical) will have to receive a compensation considering the future conditions.

Plotting the dependences L1 and L2 on the number of events allows to form the dependence of the total loss to the amount of protective events (fig. 1). In fig. 1, it can be seen that the optimal number of events in which the amount of L1 and L2 losses take the minimum value is about 3 .

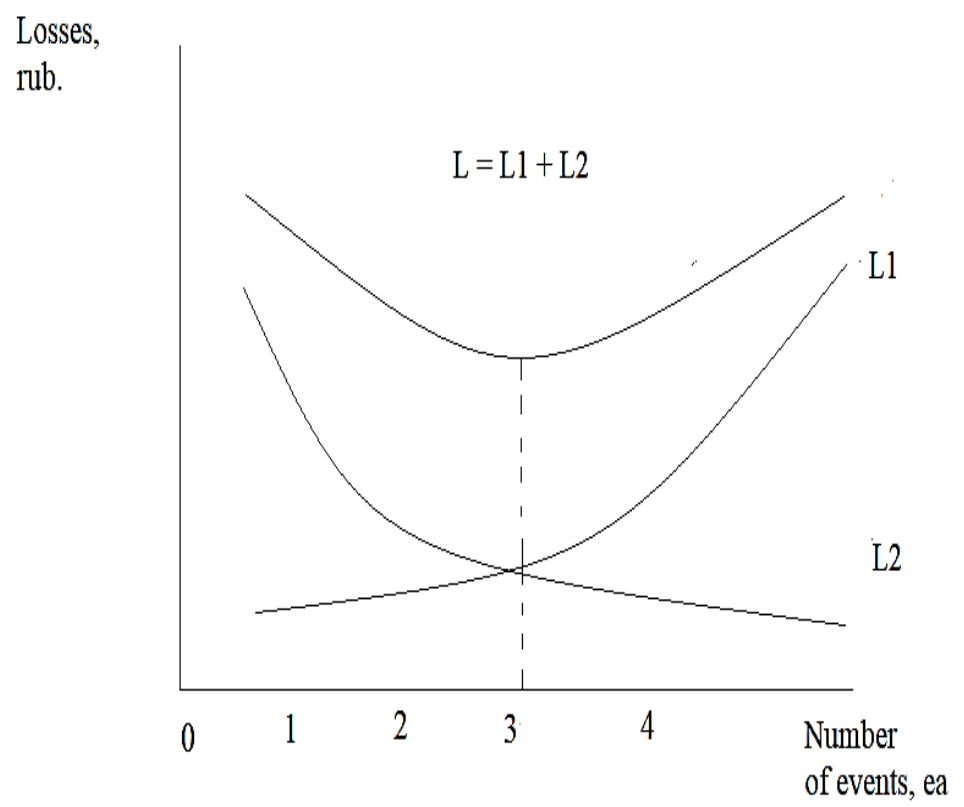

Fig. 1. Graphic model for assessing the optimal number of preventive events according to the criterion of the minimum total losses L1 and L2.

Given the system, process and situational approaches to the management of the SEE security, it is necessary to highlight such a parameter as the complexity of the object. Complexity is a measure of the unknown process [9]. The complexity of an object depends not only on the number of connections between the subsystems of the system under consideration and the nature of its activity (for example, increased explosion and fire hazard), but also on the presence of independent complex systems located nearby. The 
higher the degree of their influence on each other, the more complex the activity of the object, the more resource-intensive measures to ensure security can be. The complexity of an object from the point of view of ensuring safety must be determined on the basis of the content of influencing factors, the frequency of their manifestation, connections within the object and the relationships between the different, seemingly unrelated to each other, objects.

The more complex the system, the more economic damage can be in the event of any failure of its subsystem in the absence of proper security management. Fig. 2 shows the parametric dependences L2 (S1), L2 (S2), L2 (S3). The complexity parameter S3 has the highest degree; therefore, the parametric dependence L2 (S3) is located above the dependences L2 (S1) and L2 (S2), i.e. the amount of losses will be greater.

For each situation of SEA complexity, its optimal number of activities is determined. In fig. 2, it can be seen that the optimal number of activities, in which the sum of losses L1 and L2 will take a minimum value with the complexity of the object S1, is approximately 3 . When the complexity of the object $\mathrm{S} 2$, is equal to about 4 , and in the complexity of the object $\mathrm{S} 3$ is equal to about 5 .

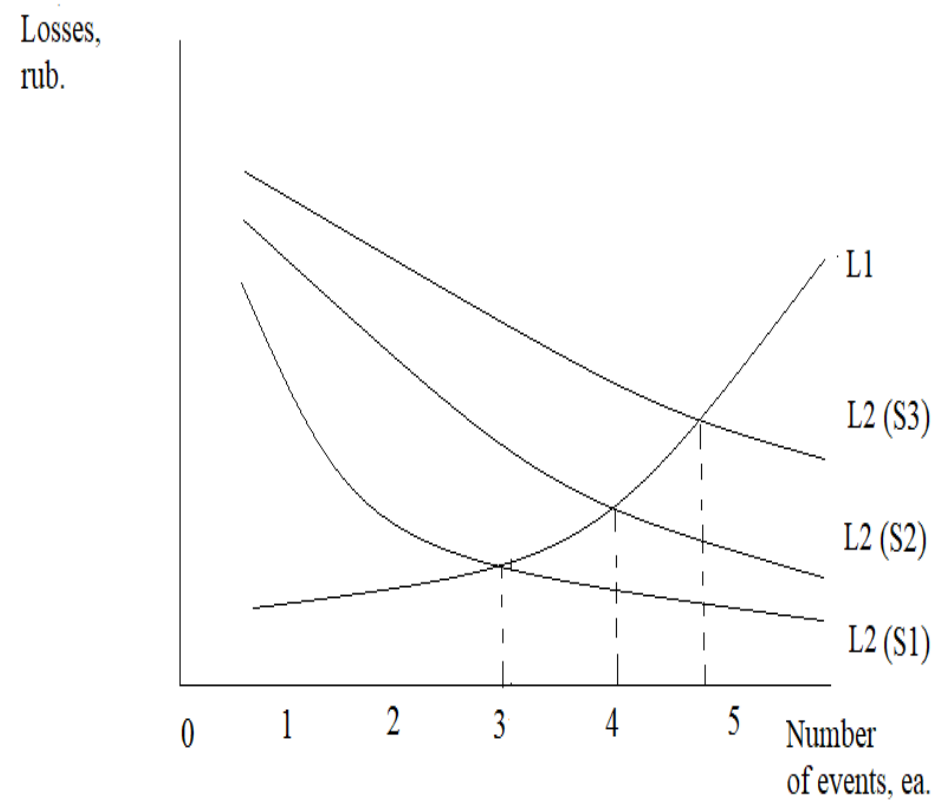

Fig. 2. Graphical model for estimating the optimal amount preventive events with parameters S1, S2 and S3.

An enterprise using the best practices and achievements of world production, creating and using its own scientific laboratories or development departments, will be more efficient and achieve better results; and this ultimately contributes to the economic development of the state itself.

Based on the definition of security, we propose the following criterion for evaluation the total economic loss (L). The higher the value of $\mathrm{L}$, the worse the ability to compete and develop, therefore, the economic security of the enterprise decreases. Economic losses accompany the process of managing any object, since it is always possible to be influenced by unexpected factors of both external and internal environment, the occurrence of which is 
difficult to predict. The content of losses is considered as overhead. They are usually not taken into account by financiers. But any process can be organized so that these losses were minimal.

When calculating losses, they must be discounted, that is, the further into the future, the more expensive the resources used to correct the situation become. In this case, there are the following situations, as a result of accidents affected people and nature.

1. Costs (losses) $S_{\text {uni0, }}$ going at a time to restore the health of the physical and / or psychological, environmental situation. Then there is no need to discount costs. At the same time, $\mathrm{S}_{\text {unio }}$ includes the cost of treatment and the lost wages of a person during the period of disability, restoration of natural resources. At the same time, the image of the organization does not suffer if the incident is not widespread.

2. If a person's health condition may require long-term treatment, then different specialists (doctors, psychologists, lawyers) must determine the severity of the harm, that is, the coefficient of harm $\mathrm{K}_{\text {harm, }}$ and the number of years of treatment. Also in the case of a negative impact on the environmental sphere. To assess $K_{\text {harm, }}$ it is necessary to classify all situations according to the criterion of the severity of a person's social and mental state. And then arrange them on a scale from $1 \%$ to $100 \%$. The heavier state, the longer period is required for the treatment and recovery of human nature, the closer should be $\mathrm{K}_{\text {harm }}$ to the value $100 \%$. If one person suffers, then his family members suffer in parallel, which can lead to a decrease in their labor productivity, and therefore to a drop in the efficiency of an enterprise and further the country's economy.

Here it is already necessary to use discounting, taking into account $K_{\text {harm }}$ and the

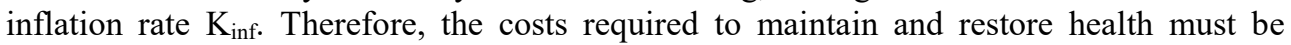
calculated using formula 1 :

$$
S_{\text {disc }}=\sum_{t=0}^{n} S_{\text {unit }}\left(\left(1+K_{\text {harm }}\right)\left(1+K_{\text {inf }}\right)\right)^{t},
$$

where $t$ is the year of calculating the costs of maintaining and restoring human health and the environmental situation; $n$ is the number of years over which the process of restoring the social, mental and physical health of a person and the ecological situation is stretched. There are situations when harm is done gradually, imperceptibly (it has a latent character), but in this case it can be calculated. It is only necessary to count from the first symptoms, which, for example, increase with the consumption of unhealthy products, that is, there is a time lag between the consumption of a service or product and the onset of the disease.

The reasoning in the article can be summarized in the form of an algorithm consisting of the following steps:

- highlighting a variety of internal and external environmental factors affecting the SEE activity;

- assessment of SEE complexity;

- forecasting failures and damage that will occur if preventive measures are not implemented;

- formation of a variety of preventive events taking into account the nature of failures (introduction of a corporate information system, improvement of the control system, modernization of the workshop, formation of an adaptive organizational structure, improvement of the SEE culture management system, etc.);

- assessment of damage L1 due to the failure of investment funds for the implementation of innovative projects when implemented, only one, two, three, etc. preventive events. Taking into account the situation, costs can be discounted;

- assessment of damage L2 in the implementation of only one, two, three, etc. preventive events. Taking into account the situation, costs can be discounted; 
- calculation of the optimal number of preventive events based on the criterion of minimum total losses L.

- organizing the implementation of the optimal number of preventive events.

\section{Conclusions}

Thus, considered in detail, the criterion L, consisting of the amount of losses L1, which is interpreted as a lost profit that could be obtained if limited financial resources were invested in an innovative project that allows to expand the market share by quickly launching a new product or service to the market and L2, assessed as the amount of damage that occurs due to the lack of the required number of preventive measures actually operating in practice. The higher the value of the total losses L, the lower the efficiency of SEE activities. In this case, the costs can be discounted, taking into account the degree of damage caused by the emergency to humans and nature, as well as the impact of inflation in the economy on the cost of resources.

It is important to understand that it is impossible to provide a full security. A normal life is always a balance between the necessary impairment of the rights and freedoms and safety. When this balance is shifting in some way (of course, to the detriment of the other), the system enters into an unstable position. And the further shifted the balance, the more dangerous is the deviation of the socio-economic system from the norm, which is fraught with unpredictable development of the situation. Management efficiency of socio-economic systems and organizational behavior is significantly increased if this theoretical position is taken into account. The possibility of development of innovative activity, and, therefore, possible to improve the external and internal life of the organization, the personality of the employee, arises on the condition that external and internal freedom is not overlooked.

\section{References}

1. L. R. Amirkhanova, Ensuring the sustainability and costeffectiveness of production activities of an enterprise, 182 (2005)

2. E. Yu. Bikmetov, L. R. Amirkhanova, U. G. Zinnurov, Turismo: Estudos E Práticas, 1, $1(2020)$

3. G. R. Jones, Organization Theory, Design and Change (2009)

4. O. Hrunyn, S. Hrunyn, Economic security of the organization (2002)

5. A. Odintsov, Economic and Information Security of Entrepreneurship (2008)

6. V. Franchuk, S. Melnyk, V. Panchenko, T. Zavora, V. Vakhlakova, J. Of Security And Sustainability Issues, 9, 336 (2020)

7. J. F. Broder, E. Tucker, Risk analysis and the security survey (2011)

8. T. D. Giles, How to develop and implement a security master plan (2009)

9. E. Olejnykova, Fundamentals of Economic Security (1997)

10. O. V. Rossoshanskaya, Creative Economy, 5, 77 (2013)

11. S. V. Bank, V. D. Sekerin, A. E. Gorokhova, N. I. Nikolaykin, A. G. Shcherbakov, International J. of Engineering \& Technology, 7(3), 210 (2018)

12. A. M. Slinkov, K. S. Didyk, Modern Scientific Research and Innovation, 12, 664 (2015)

13. D. Tyson, Security convergence: Managing enterprise security risk (2007)

14. P. Basu, S. K. Nair, European J. of Operational Research, 247(2), 596 (2015) 
15. A. Dibrova, Procedia-Social and Behavioral Sciences, 207, 280 (2015)

16. M. N. Dudin, D. D. Burkaltseva, O. S. Reznikova, O. A. Guk, S. A. Zotova, A. V. Betskov, H. S. Kilyaskhanov, International J. of Engineering \& Technology, 7(14), 283 (2018)

17. M. P. Vlasov, International J. of Innovation, Creativity and Change, 8(10), 244 (2019)

18. I. V. Kazmina, C. Y. Shafranskaya, I. I. Saenko, S. I. Kozhemov, S. R. Gayazova, E. I. Zatsarinnaya, Talent Development and Excellence, 12(3), 454 (2020)

19. L. Karpenko, O. Zhylinska, H. Dmytrenko, N. V. Poprozman, V. Koltun, J. Of Security And Sustainability Issues, 9(4), 1421 (2020) 